\section{The \\ Kurious \\ Kase of Kim \\ Kardashian's}

Korset

By Alanna McKnight

\section{KEYWORDS:}

CORSETS

DRESS REFORM

KIM KARDASHIAN

MUGLER

FETISH

\section{Abstract}

The 2019 Met Gala's theme was based on the Susan Sontag essay "Notes on Camp," and the celebrity attendees had a broad range of interpretations. The look that caused the most controversy was worn by the reality TV star Kim Kardashian, in a Thierry Mugler dress and Mr. Pearl corset. Rather than focus on the design, the first for Mugler since 2002, or how the dress fit into the theme, critics instead chose to focus on the corset and repeat a rhetoric about the controversial garment that has been recurrent for over a hundred years. There is a long tradition of opposition to corsets, including claims that the accessory is bad for the health of the wearer, that corsets are unnatural, and that they are anti-feminist. This article explores the history of corsets, health, popular culture, and fashion, using Kardashian as a contemporary source of examination. Kardashian's body is a site of controversy, much like corsets, as she wears and sells shapewear. The critique of Kardashian's use of modern shapewear reflects a long tradition of controlling women's bodies through dress reform and medical intervention, a debate the Met Gala dress reignited. 


\section{INTRODUCTION: CORSETS, CAMP, AND CONTROVERSY}

The annual Gala held at the Metropolitan Museum of Art in New York is one of the most anticipated fashion events of the year, where celebrities dress to a theme of an annual exhibit raising money for the Met's Costume Institute. The 2019 theme was based on Susan Sontag's 1964 essay "Notes on Camp," and while critics in the media felt that the celebrities in attendance were hit and miss with bringing Camp to the pink carpet, one celebrity in particular caused controversy. Kim Kardashian West attended the Gala in a custom-made Thierry Mugler dress, with a Mr. Pearl corset as the foundation, a combination that exaggerated her already curvy silhouette (Figure 1).
The dress was inspired by the 1957 film Boy on a Dolphin, specifically a scene in which Sofia Loren emerges from the water, wearing a wet, body-clinging dress, ${ }^{1}$ highlighting her famously buxom form. The Mugler dress is a feat of engineering: to mimic the look of a dripping wet garment the dress needed to be snug and was made from latex and mesh with the corseted bodysuit underneath. Kardashian has been the target of outrage because of her exaggerated figure, with claims her appearance was unrealistic. She has a long history of being attacked by journalists and on social media for wearing and promoting corsets, a garment she has worn for years to help enhance her trademark curves. The vitriol that is directed toward her is a reflection of a long tradition of misunderstanding corsetry, attempts at controlling women's bodies, and dress reform.

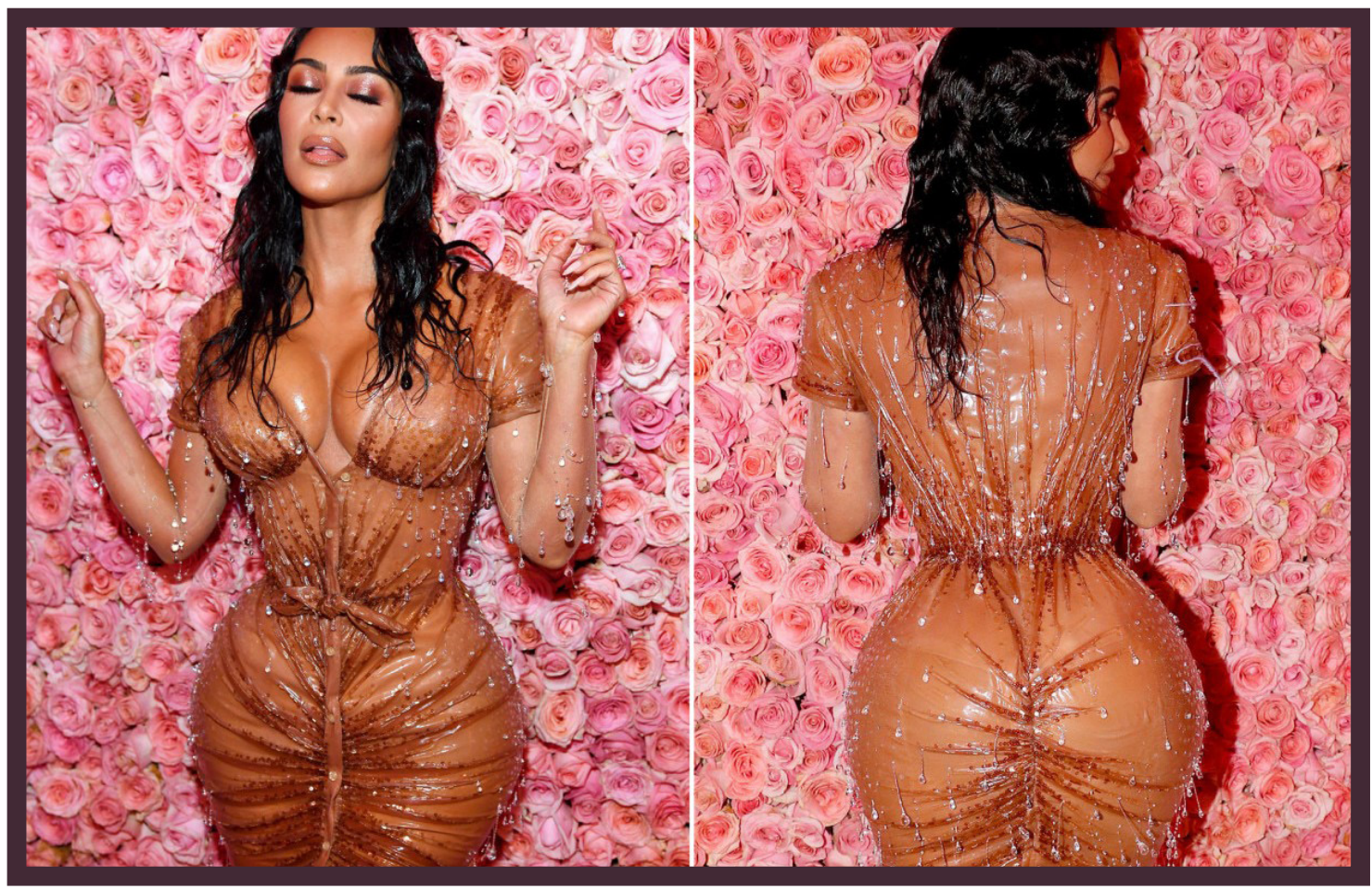

FIGURE 1 "How Kim Kardashian's 2019 Met Gala Corset Whittled her Waist". Page Six Style (May 8, 2019). Accessed May 10, 2019. https://pagesix.com/2019/05/08/how-kim-kardashians-2019-Met-gala-corset-whittled-her-waist/. 
This article will contextualize the critiques of Kardashian's figure within the history of dress reform and corsetry and argues that the media's reaction to her Met Gala dress has foundations in the nineteenth century.

Her dress acts as a site upon which the ways that women have been blamed for social and physical ailments is interrogated, while also exploring why Kardashian is a target for sartorial hate, when other celebrities are immune. Ultimately, this article will argue that Kardashian is shouldering the weight of over a century of accumulated outrage over corsets, and misdirected hate at a "famous for nothing celebrity" for her decision to create a hyper-feminine form.

In the days after the Met Gala, news outlets expressed concerns over the healthfulness of wearing a tight corset, and spectators on social media speculated that Kardashian had ribs removed as well as questioning the safety of her dress. ${ }^{2}$ The context of this critique is a costume party for the rich and famous, where celebrities like Billy Porter wore wings, and Katy Perry dressed like a hamburger. The Sontag essay that inspired the 2019 Gala states that Camp is "the love of the unnatural: of artifice and exaggeration."3 Certainly these three examples of Kardashian, Porter, and Perry express this theme of artifice and exaggeration. There is also a double standard in the critique of Kardashian's artifice, reflected through one of the attendees of the Met Gala, Ru Paul's Drag Race season 9 winner Violet Chachki. Chachki famously wears and owns corsets and even walked the runway in an episode of Drag Race with an alleged eighteeninch waist, though she was not wearing a tight lacing corset the night of the event. But there are no headlines deriding her performance as irresponsible and dangerous. Indeed, even Mr. Pearl himself has an eighteen-inch waist, ${ }^{4}$ but does not receive the backlash that Kardashian does, despite making the garment. This double standard rests in the fact that Kardashian is a more public figure, with a body that is outside the accepted standard for Hollywood. The anger towards Kardashian and corsets has also extended to critiques of her parenting skills, with headlines from The Daily Mail in 2017 accusing her of dressing her then four-year-old daughter, North, in a corset (Figure 2). ${ }^{5}$

${ }^{2}$ Melissa Minton. “How Kim Kardashian’s 2019 Met Gala Corset Whittled her Waist”. (May 8, 2019) https://pagesix.com/2019/05/08/how-kim-kardashians2019-Met-gala-corset-whittled-her-waist/

13 Susan Sontag. "Notes on Camp". Partisan Review 31:4 (Fall 1964): 515.

${ }^{4}$ Valerie Steele. Corsets: A Cultural History. (New Haven: Yale University Press, 2001): 100.

${ }^{5}$ Clemence Michallon. "I think it's Really Cute: Kim Kardashian Defends Dressing her Daughter, North, four, in a Corset-Style Dress After Social Media 
The dress in question had a lacing detail, but was not boned, nor did it provide any shape, and was certainly not comparable to the corsets young girls were trained in during the nineteenth century. Regardless, the outcry on social media was quick and furious. Images of the dress show that it does not cling to the body, let alone shape it, but the example does demonstrate the quick judgements made toward corsets with a Kardashian association. Kim Kardashian DEFENDS Dressing her Daughter, North, four, in a Corset-Style Dress After Social Media Outcry." The Daily Mail (July 12 2017). Accessed January 10 2018. https://www.dailymail.co.uk/ femail/article-4690850/OutrageNorth-West-steps-CORSET.html.

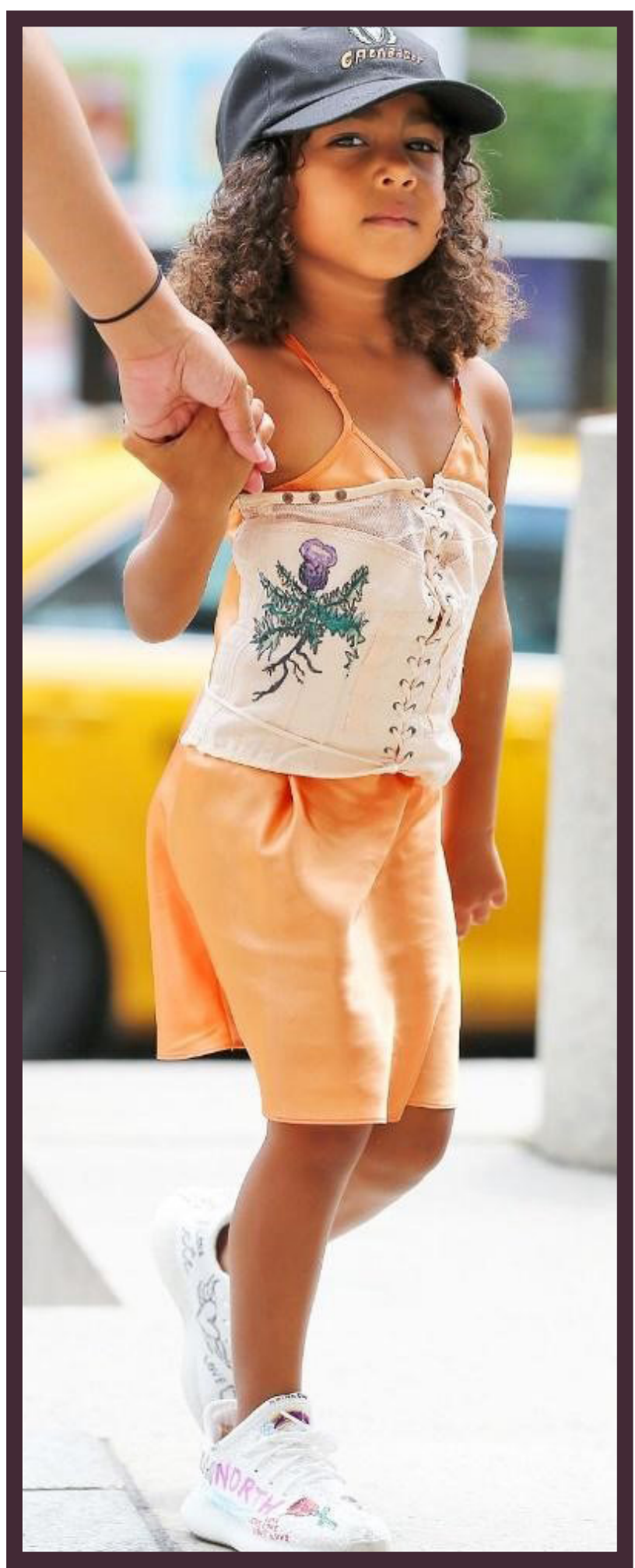




\section{CURRENT CORSETS AND BODY SHAPERS}

Mr. Pearl and Thierry Mugler have collaborated on couture designs for many years. In the 2001 book Corsets: A Cultural History, Valerie Steele describes the collaboration between Mr. Pearl and Mugler, stating that the women they dress as "Hollywood divas, goddesses, devils, and sexy robots.” With Kardashian's Met Gala dress referencing the Hollywood siren, this dress continues their tradition, as well as Sontag's sentiment on Camp that “....allied to the Camp taste for the androgynous is something that seems quite different but isn't: A relish for the exaggeration of sexual characteristics and personality mannerisms." Through highlighting her breasts with make-up, and accentuating her large hips and posterior with a corseted waist, Kardashian certainly fills this definition of Camp. The runway designs by Mugler and Mr. Pearl are not criticized as repressing women and creating an unhealthy image for girls to mimic, as Kardashian is, despite the models for a 1997 Mulger/Pearl collection walking the runway with cinched waists. Instead, observers at the time stated "that Mugler's couture work represents the creative pinnacle of fetish-inspired corset fashion." ${ }^{8}$

\section{This raises the following question: what has happened in the last twenty years to go from praising the collaboration of Mugler and Mr. Pearl, to condemning the body who wears it?}

Perhaps it is the lack of extreme shape created by these 1997 designs, as this was an era of the heroin chic model ${ }^{9}$ with small breasts and narrow hips, compared to Kardashian's diminutive height, at five-foot three inches, with seemingly disproportionate hips and breasts. The internet was in its infancy then, so access to the photos of the show are relegated to the archives and memories of dress historians or those with niche interests. 
However, as Sontag notes in a different essay, Regarding the Pain of Others: "Ideologies create substantiating archives of images, representative images, which encapsulate common ideas of significance and trigger predictable thoughts and feelings. Poster-ready photographs... are the visual equivalent of sound bites." What a general readership therefore remembers are the caricatures and medical drawings of the long-nineteenth century, often repeated in current news stories which espouse the dangers of corsetry, rather than the corset-laden runways of the 1990s by designers such as Mugler, La Croix, McQueen, Gaultier, and Westwood, though there seems to be a blind spot in the more recent memories of shapewear and fashion.

Body shapers are not a rarity in today's fashion. Products such as Spanx provide women with a foundation for off-the rack garments that are made to fit a set range of sizes to which most bodies do not conform. Body shapers come in a variety of styles and can target specific areas. They may be created for the thighs, cut like tight shorts, or extend to under the bust to maintain the mid-section. They are cut as dresses, skirts, and tubes, and are comparable to girdles and shapers worn by women from the 1920s through the 1960s, though made from contemporary materials. The most popular brand of body shaper for the past 20 years is Spanx, which were developed in the late 1990s, and became a popular staple in women's foundation garments in 2000. ${ }^{11}$ Garments referred to as "waist trainers," which target the waist specifically (much like corsets), have also made a resurgence. These are often made of latex and make false promises of weight loss. While they are referred to as corsets, they are not the rigid, heavily-boned garments that are associated with the name. They are more similar to girdles or Spanx, or garments from Columbia called fajas. 
In a 2012 New York Times article, fajas were described as a new trend in body shaping influenced by Latin American culture. The word "fajas" means "wraps" in Spanish and refers to garments which are now colloquially referred to as "corsets." These were initially worn as a post-liposuction device for minimizing swelling and ensuring skin heals correctly. Eventually, women in Colombia began wearing fajas without the liposuction. One company from New York, which used to sell fajas to spas and medical supply stores, stated that orders from the fashion world began in 2007. ${ }^{12}$ According to this company initially it was just Latina and Black women who purchased fajas, but at the time of publishing the article there was an increase in white women purchasing them as well, ${ }^{13}$ possibly due to the rise in fame of Kim Kardashian and a desire for women of all ethnicities to mimic her small waist, large breasts, and exaggerated posterior.

Previously known as the friend of and assistant to Paris Hilton, 2007 was also the year that Kim Kardashian became famous after a sex tape was leaked featuring her and singer Ray J. ${ }^{14}$ The Kardashians, who also advertise weight loss supplements, cellulite treatments, and self-branded workout videos that are intended to "tone the body while allowing you to 'flaunt your curves,"'15 extol the virtues of latex-based corsets.
In 2019 Kim was embroiled in controversy as she released her own brand of body shapers, a line called "Kimono."She has since re-named the line "Skims" after backlash accusing her of cultural appropriation. ${ }^{16}$ The Kardashians also have an exclusive contract with Ann Cherry, a company from Colombia with international reach. Kim Kardashian uses waist trainers to exaggerate her already extreme curves, allowing her to further "capitali(se) on a body that in her case is positively marked as 'exotic' without any of the burden that typically also accompany that designation." 17

\section{PATHOLOGIZING WOMEN'S BODIES}

Articles from the week following the Met Gala questioned the safety of wearing corsets, with many speculating that Kardashian had ribs removed for the event. The history surrounding the myth of rib removals is a long one, but there has been no evidence that anyone, even at the height of Victorian corsetry, ever had ribs removed. ${ }^{18}$ Within this historical context, stories about rib removals were common in the popular press, which frequently included apocryphal stories with no basis in medical fact. This is also contextualized by the nature of Victorian medicine, where even simple surgeries were extremely dangerous, with no antibiotics, and only basic anesthetics available.

${ }^{12}$ Alexandra Sastre. "Hottentot in the Age of Reality TV: Sexuality, Race and Kim Kardashian's Visible Body", Celebrity Studies 5, no. 1-2 (2014), 123.

${ }^{13}$ Sarah Maslin Nir. "Rediscovering a Shortcut to an Hourglass Figure”. (May 15, 2017). http://www.nytimes.com/2012/05/16/nyregion/with-fajas-tight-ascorsets-shortcut-to-hourglass-figure-is-rediscovered.html.

${ }^{14}$ Sastre, 124.

${ }^{15}$ Sastre, 130.

$1{ }^{16}$ Jessica Davis. "Kim Kardashian Renames Shapewear Line After Cultural Appropriation Backlash”. Harpers Bazaar. (Aug. 27, 2019). https://www.harpersbazaar.com/uk/celebrities/news/a28826733/kim-kardashian-renames-shapewear-line/. 
Yet every generation has its own celebrity story about rib removals, from Cher to Marilyn Manson. Kardashian seems to have been inducted into this bizarre club. The concerns about Kardashian's heath includes medical advice about the dangers of wearing corsets. Women's Health magazine, for example, says "super tight corsets can push the stomach beyond the diaphragm, causing reflux and interfering with breathing, and they can damage the ribs... they can also put unwanted pressure on your midsection, which limits the blood and oxygen flow to your vital organs." ${ }^{19}$ Forgetting for a moment that "unwanted pressure" does not apply to someone who willingly dressed themselves in a corset, most people who wear corsets do not tight lace. And those who do, have trained their bodies for years to accommodate the garment. It takes years of waist training with specially made corsets to whittle a waist down to a small size. This is not something the average corset, or even Spanx, wearer would ever consider. It is a body modification. Just as many people have their ears pierced, not all of those people also have their tongues bifurcated. As historian David Kunzel explains, "tight-lacing" is a practice that cannot be defined by a waist size, and indeed there "is reason to suppose that far fewer women actually practiced tight-lacing... than the dress reformers made out, exaggerating the habit for polemical reasons." 20 This conflating of the practice of tightlacing and regular corset wearing is where history is muddled, and where the idea of the Victorian woman as ignorant of her own agency is perpetuated through generations.

The concerns from Women's Health echo the medical advice given to women in the nineteenth century surrounding dress reform. Dress reform arguments were often based on questionable medical information which blamed corsets for a number of ailments, and claimed that corsets were directly related to a decline in birth rate. The fictions written by medical professionals about corsets were described in news stories; however, the journalists themselves were also often responsible for the creation of corset myths.

${ }^{19}$ Kristin Canning. "People are Freaking out About how Small Kim Kardashian's Waist Looks in her Met Gala Corset Dress". (May 7, 2019). https://www. womenshealthmag.com/life/a27394686/kim-kardashian-shapewear-corset-waist-Met-gala-dress/. 


\section{The regulation of Kardashian's body is rooted in a tradition of dress reform and a desire to control women's bodies.}

The umbrella topic of dress reform included three popular themes: heat regulation, the effects of tight clothing on organs, and the unnatural nature of fashionable clothing. ${ }^{21}$ The wearing of fashionable clothing, it was argued by reformers, caused women to introduce social and moral problems, such as defective genes, poverty, and crime. The argument towards defective heredity was framed as undoubtedly the fault of corseted women. Medical literature from Queen's University cited congestion of the blood and displaced uterus as hazards of fashionable dress. ${ }^{22} \mathrm{~A} \mathrm{Ca}^{-}$ nadian almanac, compiled by "Leading Canadian Men" called The Family Physician or, Everyman bis own Doctor, from 1889 warned readers of the dangers of prolapsed uteruses from tight lacing and heavy clothes (an unlikely concern for the "everyman" of their readership), wherein the pressure placed on the abdomen caused "the uterus to press down the vagina until it sometimes comes out externally." ${ }^{23}$ This was just one of the many possible illnesses that medical professionals of the nineteenth century blamed on corsets, a list which also included "stupidity." 24

${ }^{21}$ Eileen O'Connor. "Constructing Medical Social Authority on Dress in Victorian Canada”, Canadian Bulletin of Medical History/ Bulletin Canadien d'Histoire de la Médecine 25, no. 2 (2008), 393.

${ }^{24}$ Mel Davies. "Corsets and Conception: Fashion and Demographic Trends in the Nineteenth Century", Comparative Studies in Society and History 24, no. 4 (Oct. 1982), 628. 
One of the greater social problems that the anti-corset set exploited as propaganda was the marked decline in birth rates in the decades on either side of the turn of the century. By wearing corsets, reformers feared that "millions" of babies were potentially killed in pregnancy or after birth, causing the death of the upper and middle classes, with one American female doctor, Alice Stockham, stating that this would "leave the propagation to the coarse grained but healthy lower classes." ${ }^{25}$ This statistic regarding birth rate was later examined by Australian historian Mel Davies, for the Society of Comparative Studies in Society and History in 1982. His article "Corsets and Conception" begins with a list of possibilities for the decline in birth rates, including greater knowledge of contraception, women marrying later, changing roles of women in society, and a conscious decision by families to have fewer children for economic purposes. ${ }^{26}$ However, he dismisses all these options and instead quotes historian Lorna Duffin, asking, "Why was there an apparent explosion of female disease in the second half of the nineteenth century" if not because of corsets. ${ }^{27}$ This argument ignores the use of lead in cosmetics, ${ }^{28}$ arsenic in a number of clothing and decorative items, ${ }^{29}$ and mercury in hats, ${ }^{30}$ among other environmental poisons and toxins, as well as contagions of everyday Victorian life which affected the health and wellbeing of women. Davies also cites an article from Norah Waugh's Corsets and Crinolines that tells the story of a young woman at a "fashionable London school, where young girls had their corsets tightened one inch per month until the desired size was achieved." What Davies conveniently leaves out is the final line, "I have never suffered any ill effects myself, and, as a rule, our school was singularly free from illness." ${ }^{11}$ Regardless of the fact that prestigious London schools were not the norm for the majority of the population, Davies cherry-picked this sensationalist story of attempting to achieve a small waist, omitting the moral of the story that no harm came to the author. Also deeply troubling is the fact that Davies cites Havelock Ellis, a vocal proponent of eugenics, to support his arguments. Ellis was on record as being pro-corset, as, according to him, evolution had created a woman who was too weak to be supported on her own, and thus required the garment to fix the feebleness of the female form. ${ }^{32}$ By focusing only on dress reform, and by skewing data and citations, historians like Davies have perpetuated the rhetoric of corsets as instruments of death; and certainly, these tales make for far more interesting reading than women who were comfortable in their dress. However, this rhetoric incorrectly assumes that all women practiced tight lacing, rather than wearing their corsets to create a moderate shape.

${ }^{25}$ O’Connor, 398.

${ }^{26}$ Davies, 614.

${ }^{27}$ Davies, 623.

${ }^{28}$ Alison Matthews David. Fashion Victims: The Dangerous Dress of Past and Present. (London: Bloomsbury, 2015): 23.

${ }^{29}$ Matthews David, 81.

${ }^{30}$ Matthews David, 44.

${ }^{31}$ Norah Waugh. Corsets and Crinolines. (New York; Routledge, 1954): 141.

32 Jill Fields. "Fighting the Corsetless Evil: Shaping Corsets and Culture, 1900-1930". Journal of Social History 33:2 (199): 358. 


\section{The literature surrounding dress reform, as well as the lectures by social reformers, were loaded with statements from medical profes- sionals, warning women of the ills that might befall them if they were foolhardy enough to be more concerned with their appearance than their health.}

In 1876, a dress reform book was printed in Montreal, called Dress and Health, or How to be Strong, a Book for Ladies. This book was a compilation of works by American dress reformers. The rhetoric of this book from the outset was anti-feminist, stating that dress reform should not be conflated with the "ill-odored Women's Rights Movement," nor should it be confused with earlier attempts of dress reform such as the Bloomer costume and the "mannish" garb associated with it. ${ }^{33}$ Though the introduction states that the information included was obtained by four female medical professionals, the first chapter begins with a long quote by a male doctor, who, apart from the unspecified "unhealthfulness" of the corset, states that it is "palpably ugly,"34 a rhetoric often repeated, as it was understood that the role of women was to be visually pleasing for men. Furthermore, he states, the dress of women was complicated, and took too much time to arrange, which distracted women from their domestic duties, deprived them of sleep, and indeed gave them no time for intellectual pursuits. ${ }^{35}$ The third chapter surrounds the writing of a female doctor, Mary J. Safford-Blake. She tells several stories, tinged with nationalistic tones as demonstrated through the statement, "The physical degeneracy of the mothers will leave its impress upon sons as well as daughters; and in the end, the national strength languishes under the weakness of inheritance." ${ }^{36}$ She also includes anecdotes about her medical practice as evidence of the need for dress reform. In one example, Safford-Blake describes performing an autopsy on a woman in Vienna, who died after a brick house collapsed on her. This woman was of interest to Dr. Safford-Blake because she was not corseted. Much to her surprise, however, the deceased woman's liver had been severed in two, her ribs overlapped, and the womb, which as every medical practitioner of the nineteenth century knew, wandered about the body, was nowhere near its intended location. This displacement of internal make-up was due, not to the fact that a building had collapsed

${ }^{33}$ Dress and Health: or How to be Strong, a Book for Ladies (Montreal: John Dougall \& Son, 1876): 5. ${ }^{26}$ Davies, 614. 
on her, but rather, because this particular Viennese woman laboured while wearing a tight belt. ${ }^{37}$ If a belt could do such horrors, she argued, imagine what a full torso experiencing compression would look like.

Thirty years after Dr. Safford-Blake examined the body of the Viennese house collapse victim, an article in The Globe described a lecture by dress reformer Dr. Jennie Grey. After listening to Grey lecturing about how men are far healthier than women because of their dress, an audience member asked her why women live longer than men, if men's dress was so healthful. Her answer was "women do not use tobacco or whiskey so much." 38 The topics of temperance and dress reform were often championed by the same people. For example, in 1901, Mrs. Carrie Nation, "Famous saloon smasher," concluded her talk at Toronto's Massey Hall by stating that corsets "were the instruments of the devil for squeezing the life out of women and destroying the natural beauty of their form." ${ }^{39}$ The concept of "nature" and "natural law" which is present in most dress-reform propaganda invokes a sense of Darwinian theory, which again speaks to a eugenicist branch of medical intervention not uncommon during the period. ${ }^{40}$

Though the public today feels comfortable criticizing Kardashian for medical problems that allegedly come from corset use, this is the same public who criticized and judged her for requiring a surrogate to carry her third and fourth children. Some critics derided her choice to have children via surrogate as "an easy way out." ${ }^{41}$ Kardashian experienced placenta accrete during her second pregnancy, which makes subsequent pregnancies extremely dangerous and potentially fatal. ${ }^{42}$ Her critics felt it would be better for her to carry a child and risk her own life for a performance of what is perceived as womanhood. Yet in constructing a hyperfeminine figure through corsetry and doing less damage than pregnancy, she is open for criticism.

\section{As mentioned above, doctors} advised that corsets push the stomach beyond the diaphragm, can damage ribs, and limit blood and oxygen flow to organs. As a result of pregnancy, cardiac output increases by thirty to fifty percent, and the cardiovascular system may be at risk due to increased output. ${ }^{43}$ The growth of the fetus causes the diaphragm to be elevated four centimeters, and the subcostal angle of the ribcage increases by forty degrees, while lung capacity is reduced by ten to twenty-five percent. ${ }^{44}$ Among these and a host of other changes, organs such as kidneys, liver, and stomach are all displaced by the expanding uterus. ${ }^{45}$ All of these biological changes during pregnancy are similar to medical concerns about corsets. Despite this, critics of Kardashian would rather she carry her children and risk complications but chastise her for her wearing a corset at a costume party.

${ }^{37}$ Dress and Health, 20.

38 "Pretty, but Unhealthy: Corsets Create Fat and Trains Nurture Germs". The Globe, (Toronto, ON), April 12, 1905, p. 14.

39 "Go, Smash, Says Carrie". The Globe, (Toronto, ON), Sept. 19, 1902 p. 12.

${ }^{40}$ Angus McLaren. Our Own Master Race: Eugenics in Canada, 1885-1945 (Toronto: McClelland \& Stewart Inc., 1990): 23.

${ }^{41}$ Meghan De Maria. "Kim Kardashian has a Message for Haters who Think Surrogacy was an Easy Way Out" (Nov. 15, 2017). https://www.refinery29.com/ en-us/2017/11/181216/kim-kardashian-response-surrogacy-critics.

${ }^{42}$ Jamie Primeau. "Kim Kardashian Calls Surrogate Rumours 'Super Invasive' and She’s Not Wrong”. (Sept. 9, 2017). https://www.bustle.com/p/kim-kardashian-calls-surrogate-rumors-super-invasive-shes-not-wrong-2305663.

${ }^{43}$ EK Tan and EL Tan. "Alterations in Physiology and Anatomy During Pregnancy". Best Practices E̋ Research Clinical Obstetrics and Gynaecology 27 (2013): 792.

${ }^{44} \mathrm{Tan}$ and Tan, 793. 
FETISH AND CELEBRITY: MODERN CORSETS

\section{Prior to the introduction of fajas to popular} fashion, and well before Kardashian fame, corsets were popular among members of counterculture and fetish communities, made by independent, local designers for decades, as well as being popular on haute couture runways.

Before the internet made corset shopping simple, people who wished to cinch used mail-order catalogues, selected from the back of adult magazines, joined "corset clubs" with newsletters, or visited local designers or fetish shops to purchase corsets. Corsets returned to mainstream fashion thanks, in part, to the fetish community. The late 1980s saw a rise in the concept of body modification, and publications such as Piercing Fans International Quarterly often had images of tight-laced women, alongside interviews with Ethel Grainger, a Guinness World Record holder for tight-lacing down to 13 inches. The magazine Body Play was published by Fakir Musafar, the late performance artist who was known for his fetish-themed performance art with fleshhook suspensions, piercings, scarification, and tight-lacing. Musafar is credited with creating a movement in the $1970 \mathrm{~s}^{46}$ that helped to normalize body piercings and tattoos, and to varying degrees of acceptance, corsets, albeit specifically tightlacing; however, it is critical to note that Musafar appropriated global Indigenous practices and rituals surrounding piercings, tattoos, and pain at the same time. In the 1990s there was a proliferation of corset makers, including Dark Garden in San Francisco, who recently opened a second location in New Orleans, and Versatile Fashions, also in California, both of which are still operating today. The 1990s also saw a shift in fetish publications, which were more accessible and glossy. Publications such as Skin Two were inspirational to a younger, more alternative fetish crowd. This was the height of the rave scene and the heyday of bands like Nine Inch Nails having regular air play on MTV, who performed in bondage-themed music videos. 
The evolution in attitudes toward corsets in media is reflected in Dick Hebdige's seminal text Subculture. Corsets and waist training were simultaneously relegated to the realm of counter culture (goths, punks, and fetish niches), while the media has been steadily normalizing corsets, with headlines in fashion publications declare its return every few years. ${ }^{47}$ At the same time, pop stars are often dressed in corsets for music videos and editorials, from Janet Jackson, Madonna, and Brittney Spears in the 1990s, to Rhianna and Dita Von Teese in the 2010s, performers dress in outfits that were relegated to fetish photography forty years ago. As Hebdige suggests, the media incorporates aspects of subculture or historical fantasies in stories, or in fashion editorials, which expose an audience to these fashions. ${ }^{48}$ The proliferation of counter-culture fashion into mainstream and high fashion begins with small companies, which is then translated into commodities and made available. The Kardashians selling waist trainers is equivalent to Punk fashion being incorporated into a 1977 edition of Cosmopolitan. ${ }^{49}$ The parallels of subculture that Hebdige wrote about and the integration of corsets into common fashion are based on youth culture, but also race and cultural appropriation. White working-class youth in England were influenced by black ska culture, just as now white women are emulating Latina fashion with fajas.

\section{Corsets have also} graced the runways of haute couture fashion shows, and have been a favourite garment for designers of the past thirty years, such as Alexander McQueen, Jean-Paul Gaultier, Thierry Mugler, Christian Lacroix, and Vivienne Westwood.

They all have their personal take on the corset, for example as part of an elegant evening gown by Lacroix, a racy stage outfit for Madonna by Gaultier, or a hard leather armour by $\mathrm{McQueen}$. These designers have contributed to re-normalizing the presence of corsetry in the media, and in the collective consciousness of consumers.

There is another double standard to consider, apart from the critiques of bodies at the Met Gala. The burlesque performer, Dita von Teese, is referenced 
in many articles about Kardashian's dress, referring to in one as the "wasp-waisted burlesque superstar." This is because Mr. Pearl is one of her favourite corset makers. Von Teese (real name Heather Renee Sweet), is credited with re-popularizing the performance of burlesque, and is a great lover and wearer of corsets, both in her on-stage performances and in everyday life. Her love of lingerie extends to her own fashion line. Though they both wear Mr. Pearl, and both enjoy the use of corsetry, von Teese has not experienced anywhere near the levels of vitriol that Kardashian has. Perhaps this is because her career is based on her sexuality, as opposed to the alleged "nothing" that Kardashian is famous for. Though Kardashian rose to fame based on her sex tape, von Teese has made a career on burlesque which parodies feminine identity, much like Violet Chachki. She also has a less exaggerated body, though she is similarly as diminutive as Kardashian at five-foot five-inches. Celebrity media polices "the physiological status, style and appearances of female celebrities - regardless of their association (or otherwise) with more 'meritocratic' notions of talent and fame." ${ }^{51}$ By mentioning von Teese without critique in articles shaming Kardashian, celebrity writers create a double standard in what is allowed for women. In celebrating von Teese as part of counter culture, despite her wedding to now ex-husband Marilyn Manson being covered by Vogue in 2005, writers implicitly state that women should be held at different standards, depending on why they are famous and what their bodies look like.

\section{CONCLUSION}

Kim Kardashian is no stranger to controversy, from the sex-tape that launched her career, to her days-long marriage to Kris Humphries in 2011, to her current marriage to Kanye West. Controversy is a family legacy, as the daughter of OJ Simpson's defence attorney. 
It has been speculated by gossip columns that her exaggerated hips and posterior have been surgically enhanced, and she has been open about the use of waist trainers to create her narrow waist. It is no wonder, then, that the Thierry Mugler and Mr. Pearl dress Kardashian wore to the 2019 Met Gala drew negative attention. Rather than praise the designers, the media spread false information about corsets, as well as the age-old fiction of rib removal. In an era of social media, the proliferation of opinions from an uninformed reading public furthered the condemnation of corsetry. The critiques of Kardashian's dress ranged from not fitting the theme of Camp, to creating an unrealistic figure. These critiques were not equally placed on other attendees who either exaggerated their bodies for the theme or obscured them completely with costumes.

\section{It becomes obvious then, that the complaints are less about corsets, and are rather part of the long tradition of controlling and critiquing women's bodies.}

Masked under a concern for medical well-being, these critiques of modern corsetry are based in propaganda from anti-feminist dress reform movements. 
“Go Smash, Says Carrie.” The Globe, (Toronto, ON), Sept. 19, 1902.

"Pretty but Unhealthy: Corsets Create Fat and Trains Nurture Germs." The Globe, (Toronto, ON), April 12, 1905.

Arnold, Rebecca. "Heroin Chic.” Fashion Theory 3:3 (Sept. 1999): 279-295.

Bordo, Susan. Unbearable Weight: Feminism, Western Culture and The Body. Berkley: University of California Press, 2003.

Canning, Kristin. "People are Freaking Out About How Small Kim Kardashian's Waist Looks in her Met Gala Corset Dress," Women's Health (May 7, 2019). Accessed May 10, 2019. https://www.womenshealthmag.com/life/a27394686/kim-kardashian-shapewear-corset-waist-Met-gala-dress/.

Davis, Mel. "Corsets and Conception: Fashion and Demographic Trends in the Nineteenth Century." Comparative Studies in Society and History 24:4 (Oct. 1982): 611-641.

Davis, Jessica. "Kim Kardashian Renames Shapewear Line After Cultural Appropriation Backlash: She Originally Called it 'Kimono.” Harpers Bazaar (Aug. 27, 2019). Accessed February 10, 2020. https://www.harpersbazaar.com/uk/celebrities/ news/a28826733/kim-kardashian-renames-shapewear-line/.

De Maria, Meghan. "Kim Kardashian Has a Message for Haters who Think Surrogacy Was an Easy Way Out.” Refinery29 (Nov. 15, 2017). Accessed May 12, 2019. https://www.refinery29.com/en-us/2017/11/181216/kim-kardashian-response-surrogacy-critics.

Dress and Health; or How to be Strong, a Book for Ladies. Montreal: John Dougall \& Son, 1876.

Fairclough, Kirsty. "Fame is a Losing Game: Celebrity Gossip Blogging, Bitch Culture and Postfeminism.” Genders 48 (Dec 2008).

Fields, Jill. "Fighting the Corsetless Evil': Shaping Corsets and Culture, 1900-1930." Journal of Social History 33, no. 2 (1999): 355-84.

Gonzales, Erica. “Kim Kardashian Wins for Tightest Dress at the Met Gala”. Harper's Bazaar (May 6, 2019). Access May 10, 2019. https://www.harpersbazaar.com/ celebrity/red-carpet-dresses/a27377298/kim-kardashian-Met-gala-2019/.

Hebdige, Dick. Subculture: The Meaning of Style. London: Routledge Press, 1979.

Kunzle, David. "Dress Reform as Antifeminism: A Response to Helene E. Robert's 'The Exquisite Slave: The Role of Clothes in the Making of the Victorian Woman”. Signs: Journal of Women in Culture and Society 2:4 (Spring, 1977): 570-579.

Marine, Brooke. "Kim Kardashian's Controversial 2019 Met Gala Look, Explained.” W Magazine (May 7, 2019). Accessed May 10, 2019. https://www.wmagazine. com/story/kim-kardashian-Met-gala-corset-mugler-mr-pearl. 
Maslin Nir, Sarah. "Rediscovering a Shortcut to an Hourglass Figure". The New York Times (May 15, 2017). Accessed April 4, 2018. http://www.nytimes. com/2012/05/16/nyregion/with-fajas-tight-as-corsets-shortcut-to-hourglassfigure-is-rediscovered.html.

Matthews David, Alison. Fashion Victims: The Dangerous Dress of Past and Present. London: Bloomsbury, 2015.

McLaren, Angus. Our Own Master Race: Eugenics in Canada, 1885-1945. Toronto: McCLelland \& Stewart Inc., 1990.

Michallon, Clemence. "I think It's Really Cute: Kim Kardashian DEFENDS Dressing her Daughter, North, four, in a Corset-Style Dress After Social Media Outcry”. The Daily Mail (July 12, 2017). Accessed January 10, 2018. https://www.dailymail.co.uk/femail/article-4690850/Outrage-North-West-steps-CORSET. $\underline{\text { html. }}$

Minton, Melissa. "How Kim Kardashian's 2019 Met Gala Corset Whittled her Waist". Page Six Style (May 8, 2019). Accessed May 10, 2019. https://pagesix. com/2019/05/08/how-kim-kardashians-2019-Met-gala-corset-whittled-herwaist/.

O’Connor, Eileen. "Constructing Medical Social Authority on Dress in Victorian Canada". Canadian Bulletin of Medical History/Bulletin Canadien d'Histoire de la Medecine 25:2 (2008): 391-406.

Primeau, Jaime. “Kim Kardashian Calls Surrogate Rumors 'Super Invasive' \& She's not Wrong.” Bustle (Sept. 9, 2017). Accessed May 12, 2019. https://www.bustle. com/p/kim-kardashian-calls-surrogate-rumors-super-invasive-shes-notwrong-2305663.

Sastre, Alexandra. "Hottentot in the Age of Reality TV: Sexuality, Race and Kim Kardashian's Visible Body," Celebrity Studies 5, no. 1-2 (2014).

Sontag, Susan. "Notes on 'Camp.” Partisan Review 31:4 (Fall 1964): 515-530.

Sontag, Susan. Regarding the Pain of Others. New York: Picador, 2003.

Steele, Valerie. Corsets: A Cultural History. New Haven: Yale University Press, 2001.

Tan, Eng Kien and Eng Loy Tan. "Alterations in Physiology and Anatomy During Pregnancy," Best Practices \& Research Clinical Obstetrics and Gynaecology 27 (2013): 791-802.

Vale, V and Andrea Juno. Modern Primitives: An Investigation into Contemporary Adornment and Ritual. San Francisco: RE/Search Publications, 1989.

Waugh, Norah. Corsets and Crinolines. New York: Routledge, 1954.

Zanette, Maria Carolina and Daiane Scaraboto. "From the Corset to Spanx: Shapewear as a Marketplace Icon." Consumption Markets E' Culture 22:2 (July 2018): 183199. 


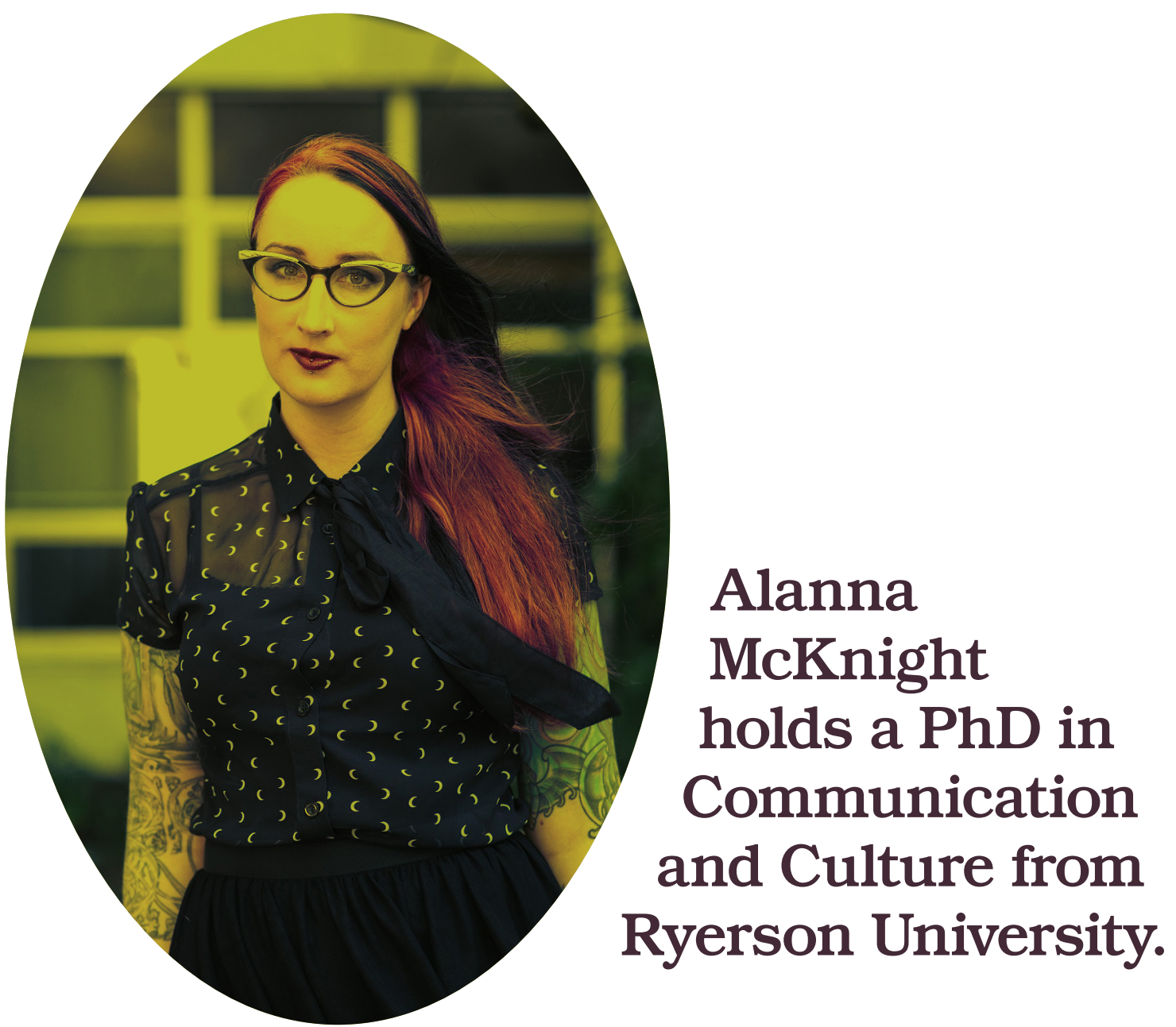

She has been researching the intersection of fashion and labour in nineteenth-century Toronto, Canada for the past fifteen years, taking particular interest in the experience of women employed in the needle trades. Her doctoral dissertation engaged in an extended case study of the manufacturing and consumer centres of Toronto during this moment of history to argue that corsets are a site of feminist agency - a stark contradiction to common media portrayals of the garment. Her academic work is enriched by her former career as a theatre costumer, and she has been an avid wearer of the types of corsets she studies for the majority of her life.

\section{ARTICLE CITATION}

McKnight, Alanna. "The Kurious Kase of Kim Kardashian's Korset." Fashion Studies, vol. 3, no. 1, pp. 1-20, https://www.fashionstudies.ca/the-kurious-kase-of-kim-kardashians-korset, https://doi.org/10.38055/FS030110. 


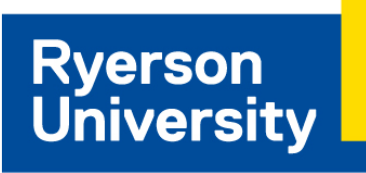

Fashion

Faculty of Communication

\& Design

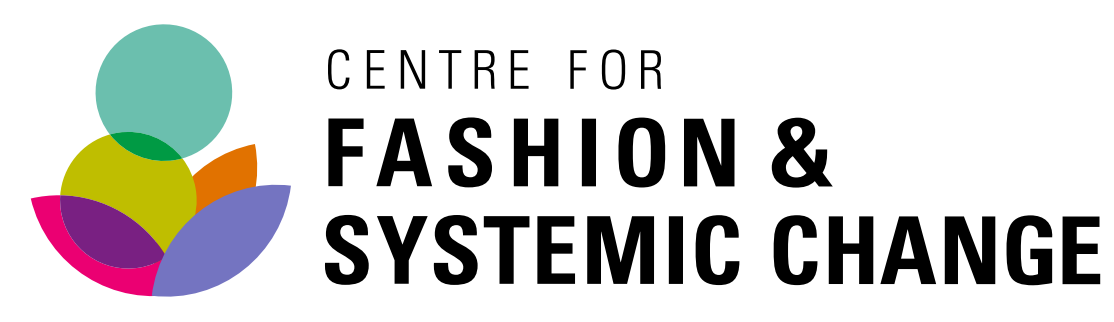

Froms SH/ON

\section{ISSN 2371-3453}

Copyright (@) 2020 Fashion Studies - All Rights Reserved

Creative Commons Attribution-NonCommercial-NoDerivatives 4.0 International (CC BYNC-ND 4.0) license (see: https://creativecommons.org/licenses/by-nc-nd/4.0/) 